\title{
Reoperation After Cervical Disc Arthroplasty Versus Anterior Cervical Discectomy and Fusion: A Meta-analysis
}

\author{
Zhao-Ming Zhong MD, Shi-Yuan Zhu MS, Jing-Shen Zhuang MS, \\ Qian Wu MD, Jian-Ting Chen MD
}

Received: 7 August 2015/Accepted: 8 January 2016/Published online: 1 February 2016

(C) The Association of Bone and Joint Surgeons (B) 2016

\begin{abstract}
Background Anterior cervical discectomy and fusion is a standard surgical treatment for cervical radiculopathy and myelopathy, but reoperations sometimes are performed to treat complications of fusion such as pseudarthrosis and adjacent-segment degeneration. A cervical disc arthroplasty is designed to preserve motion and avoid the shortcomings of fusion. Available evidence suggests that a cervical disc arthroplasty can provide pain relief and functional improvements similar or superior to an anterior cervical discectomy and fusion. However, there is controversy regarding whether a cervical disc arthroplasty can reduce the frequency of reoperations.

Questions/purposes We performed a meta-analysis of randomized controlled trials (RCTs) to compare cervical

Each author certifies that he or she, or a member of his or her immediate family, has no funding or commercial associations (eg, consultancies, stock ownership, equity interest, patent/licensing arrangements, etc) that might pose a conflict of interest in connection with the submitted article.

All ICMJE Conflict of Interest Forms for authors and Clinical Orthopaedics and Related Research ${ }^{\mathbb{R}}$ editors and board members are on file with the publication and can be viewed on request. Clinical Orthopaedics and Related Research ${ }^{\mathbb{R}}$ neither advocates nor endorses the use of any treatment, drug, or device. Readers are encouraged to always seek additional information, including FDAapproval status, of any drug or device prior to clinical use.
\end{abstract}

Electronic supplementary material The online version of this article (doi:10.1007/s11999-016-4707-5) contains supplementary material, which is available to authorized users.

Z.-M. Zhong ( $₫)$, S.-Y. Zhu, J.-S. Zhuang, Q. Wu, J.-T. Chen Department of Spinal Surgery, Nanfang Hospital, Southern

Medical University, 1838 North Guangzhou Avenue,

Guangzhou 510515, China

e-mail: zhongzm@smu.edu.com disc arthroplasty with anterior cervical discectomy and fusion regarding (1) the overall frequency of reoperation at the index and adjacent levels; (2) the frequency of reoperation at the index level; and (3) the frequency of reoperation at the adjacent levels.

Methods PubMed, EMBASE, and the Cochrane Register of Controlled Trials databases were searched to identify RCTs comparing cervical disc arthroplasty with anterior cervical discectomy and fusion and reporting the frequency of reoperation. We also manually searched the reference lists of articles and reviews for possible relevant studies. Twelve RCTs with a total of 3234 randomized patients were included. Eight types of disc prostheses were used in the included studies. In the anterior cervical discectomy and fusion group, autograft was used in one study and allograft in 11 studies. Nine of 12 studies were industry sponsored. Pooled risk ratio (RR) and associated 95\% CI were calculated for the frequency of reoperation using random-effects or fixed-effects models depending on the heterogeneity of the included studies. A funnel plot suggested the possible presence of publication bias in the available pool of studies; that is, the shape of the plot suggests that smaller negative or nodifference studies may have been performed but have not been published, and so were not identified and included in this meta-analysis.

Results The overall frequency of reoperation at the index and adjacent levels was lower in the cervical disc arthroplasty group $(6 \% ; 108 / 1762)$ than in the anterior cervical discectomy and fusion group (12\%; 171/1472) (RR, 0.54; 95\% CI, 0.36-0.80; p = 0.002). Subgroup analyses were performed according to secondary surgical level. Compared with anterior cervical discectomy and fusion, cervical disc arthroplasty was associated with fewer reoperations at the index level (RR, 0.50; 95\% CI, 0.37- 
$0.68 ; \mathrm{p}<0.001)$ and adjacent levels (RR, 0.52; 95\% CI, 0.37-0.74; $\mathrm{p}<0.001$ ).

Conclusions Cervical disc arthroplasty is associated with fewer reoperations than anterior cervical discectomy and fusion, indicating that it is a safe and effective alternative to fusion for cervical radiculopathy and myelopathy. However, because of some limitations, these findings should be interpreted with caution. Additional studies are needed.

Level of Evidence Level I, therapeutic study.

\section{Introduction}

Anterior cervical discectomy and fusion is widely accepted as a standard surgical treatment for cervical spondylosis with radiculopathy or myelopathy refractory to conservative management $[4,17]$. This technique allows direct decompression of the neural elements and generally is accompanied by interbody fusion and anterior plate stabilization. Despite its widespread acceptance, reoperations may be required to treat complications of fusion such as pseudarthrosis and adjacent-segment degeneration. van Eck et al. [39] reviewed 672 patients undergoing anterior cervical discectomy and fusion and found that the reoperation rate was $15 \%$ within an average 31 months of followup; the adjacent-segment degeneration and pseudarthrosis were the most common reasons for reoperation. Hilibrand et al. [21] reported symptomatic adjacent-segment degeneration occurred with an annual risk of 3\% after anterior cervical discectomy and fusion. Recently, Lee et al. [24] reported adjacent segments underwent surgical treatment at an annual rate of $2 \%$ after cervical fusion and predicted that $22 \%$ of patients would need a reoperation for adjacent-segment degeneration within 10 years.

The cervical disc arthroplasty is designed to maintain disc space height and motion at the index segment and prevent abnormal loading stresses and motion at adjacent segments that theoretically lead to accelerated degeneration $[12,13]$. During the past decade, the cervical disc arthroplasty has emerged as an alternative to fusion and has been shown to provide the pain relief and functional improvements similar or superior to those of anterior cervical discectomy and fusion in FDA Investigational Device Exemption clinical trials [5, 8, 10, 22, 30, 32, 35, 38, 44]. Owing to its biomechanical advantages, the cervical disc arthroplasty may be associated with less adjacent-segment degeneration. Furthermore, it avoids the potential of pseudarthrosis, anterior cervical plate-related complications, and cervical immobilization. However, the association between cervical disc arthroplasty and lower risk of adjacent-segment degeneration is not consistently supported [23, 29, 33]. A recent meta-analysis by Luo et al.
[25] found that the cervical disc arthroplasty had significantly less adjacent-segment degeneration compared with anterior cervical discectomy and fusion. Their findings, however, were in disagreement with those of Verma et al. [40] and Yang et al. [41] who reported no difference in the rate of adjacent-segment degeneration between the two groups. These published meta-analyses were based on small sample sizes and short-term studies. Therefore, strong evidence is needed that is based on the latest highquality studies to analyze the potential benefits of cervical disc arthroplasty. Reoperation is a definitive endpoint to evaluate the safety of new surgical technologies such as cervical disc arthroplasty $[1,3]$ and also is an important metric to quantify cost-effectiveness of treatments [31]. Reoperation after cervical disc arthroplasty has been attracting the attention of investigators since several cervical artificial discs have received FDA approval for implantation. Some FDA Investigational Device Exemption trials and a retrospective study have suggested that patients who underwent cervical disc arthroplasty had fewer reoperations than those treated with anterior cervical discectomy and fusion [5, 10, 22, 31, 38, 44]. However, two other FDA Investigational Device Exemption trials showed that the secondary surgical procedures were not significantly different between the two groups at 24 months $[8,19]$ and longer-term followups [35]. Notably, a higher frequency of reoperation in the cervical disc arthroplasty group (8\%) compared with the anterior cervical discectomy and fusion group (2\%) was documented in a retrospective study based on the US Nationwide Inpatient Sample database [28]. Therefore, controversy remains regarding whether the cervical disc arthroplasty is associated with lower frequency of reoperation compared with the anterior cervical discectomy and fusion.

To further clarify these issues, we performed a metaanalysis to compare cervical disc arthroplasty with anterior cervical discectomy and fusion with respect to (1) the overall frequency of reoperation at the index and adjacent levels; (2) the frequency of reoperation at the index level; and (3) the frequency of reoperation at the adjacent levels.

\section{Materials and Methods}

Inclusion and Exclusion Criteria

Our meta-analysis was conducted in accordance with the Preferred Reporting Items for Systematic Reviews and Meta-Analyses (PRISMA) guidelines [27]. Studies were eligible for inclusion if they met the following criteria: randomized controlled trials (RCTs) comparing cervical disc arthroplasty with anterior cervical discectomy and fusion for cervical spondylosis with radiculopathy or 
myelopathy; a study population 18 years and older; a minimum 2-year followup; and investigation of the rates of secondary surgeries. Studies were excluded if they met the following criteria: nonrandomized studies, retrospective studies, reviews, commentaries, meta-analyses, and animal studies; duplicate publications of one trial; and single-site data as part of a multicenter trial.

\section{Search Strategy}

A comprehensive literature search was performed in PubMed, EMBASE, and Cochrane Central Register of Controlled Trials databases dated up to June 26, 2015. There was no language restriction. The following search terms were used: cervical, artificial disc, arthroplasty, replacement, fusion, arthrodesis, secondary surgery, reoperation, revision, randomized controlled trial (Appendix 1. Supplemental material is available with the online version of $C O R R^{\circledR}$.). The reference lists of all relevant retrieved articles and reviews were searched manually to identify additional studies that might have been missed.

However, it was difficult to identify unpublished studies which were not included in this meta-analysis.

\section{Study Selection}

Study selection was performed independently by two reviewers (ZMZ and SYZ). Disagreements were resolved by consensus or consultation with a third reviewer (JTC). Our literature search identified a total of 195 potentially relevant publications. After removing 70 duplicates, the titles and abstracts of 125 publications were screened. At this stage, studies that did not fulfill the inclusion criteria in any manner were excluded. After excluding 82 publications, the full text was assessed in the remaining 43 studies for eligibility criteria (Appendix 1. Supplemental material is available with the online version of $C O R R^{\circledR}$.). Finally, 12 eligible RCTs were included in our systematic review and meta-analysis [5, 8, 10, 22, 30, 34, 35, 37, 38, 42-44]. The study selection is shown in the PRISMA flowchart (Fig. 1).

\section{Data Extraction}

Study characteristics and secondary surgical outcomes were extracted independently by two reviewers (ZMZ and QW) using a data extraction form, with discrepancies being arbitrated by consensus with a third reviewer (JTC). Information extracted from each study included study design, number of participants, study setting, patient characteristics, sample size, followup duration, and reoperation at the index and adjacent levels. In three included studies [10, 38, 44], more-detailed information regarding the reoperations is available in their companion publications, in which the reoperation events are reported [2, 9, $11]$.

In the current study, we defined reoperation as revision, removal, supplemental fixation, additional surgery at the index level, or additional surgery for adjacent-level disease. Revision was the procedure to modify or adjust the original implant without removal of the entire construct. An example of this type of procedure would be repositioning of the implant. Removal was the procedure in which one or more components of the original implant configuration was removed. For example, removal of the disc prosthesis and replacement with an interbody cage and anterior plate would be classified as removal surgery. Supplemental fixation was the procedure of implanting additional instrumentation, such as posterior plating. Additional surgery at the index level was any surgical procedure that was not classified as a revision, removal, or supplemental fixation.

\section{Study Characteristics}

All 12 studies included in this meta-analysis were parallelgroup randomized trials, eight were conducted in the United States [5, 8, 10, 22, 30, 35, 38, 44], and the other four were done in Asia and Europe [34, 37, 42, 43] (Table 1). The years of publication ranged from 2011 to 2015, and the lengths of followup ranged from 2 to 7 years. Sample sizes ranged from 101 to 540, and a total of 3234 patients (1762 in the cervical disc arthroplasty group and 1472 in the anterior cervical discectomy and fusion group) were enrolled in the 12 studies. Disc prostheses used to treat one- or two-level cervical disc disease, including the Mobi-C ${ }^{\circledR}$ (LDR Medical, Troyes, France), Bryan ${ }^{\circledR}$ (Medtronic Sofamor Danek, Memphis, TN, USA), Kineflex|C ${ }^{\mathrm{TM}}$ (Spinal Motion Inc, Mountain View, CA, USA), Dis$\operatorname{cover}^{\circledR}$ (DePuy Spine, Raynham, MA, USA), Prestige ${ }^{\circledR}$ ST (Medtronic Sofamor Danek, Memphis, TN, USA), ProDisc ${ }^{\circledR}-\mathrm{C}$ (Synthes Inc, West Chester, PA,USA), SECURE $^{\circledR}$-C (Globus Medical, Audubon, PA, USA), and PMC $^{\circledR}$ (NuVasive Inc, San Diego, CA, USA). Bone graft and anterior plating were used in the control group. Autograft was used in one study [37] and allografts were used in the other 11 studies. Ten studies reported the secondary surgical procedures at the index level and 11 reported the secondary surgical procedures at the adjacent level. Most of the included studies were multicenter trials $[5,8,10,22,30,35,37,38,42-44]$; only one was a single- 


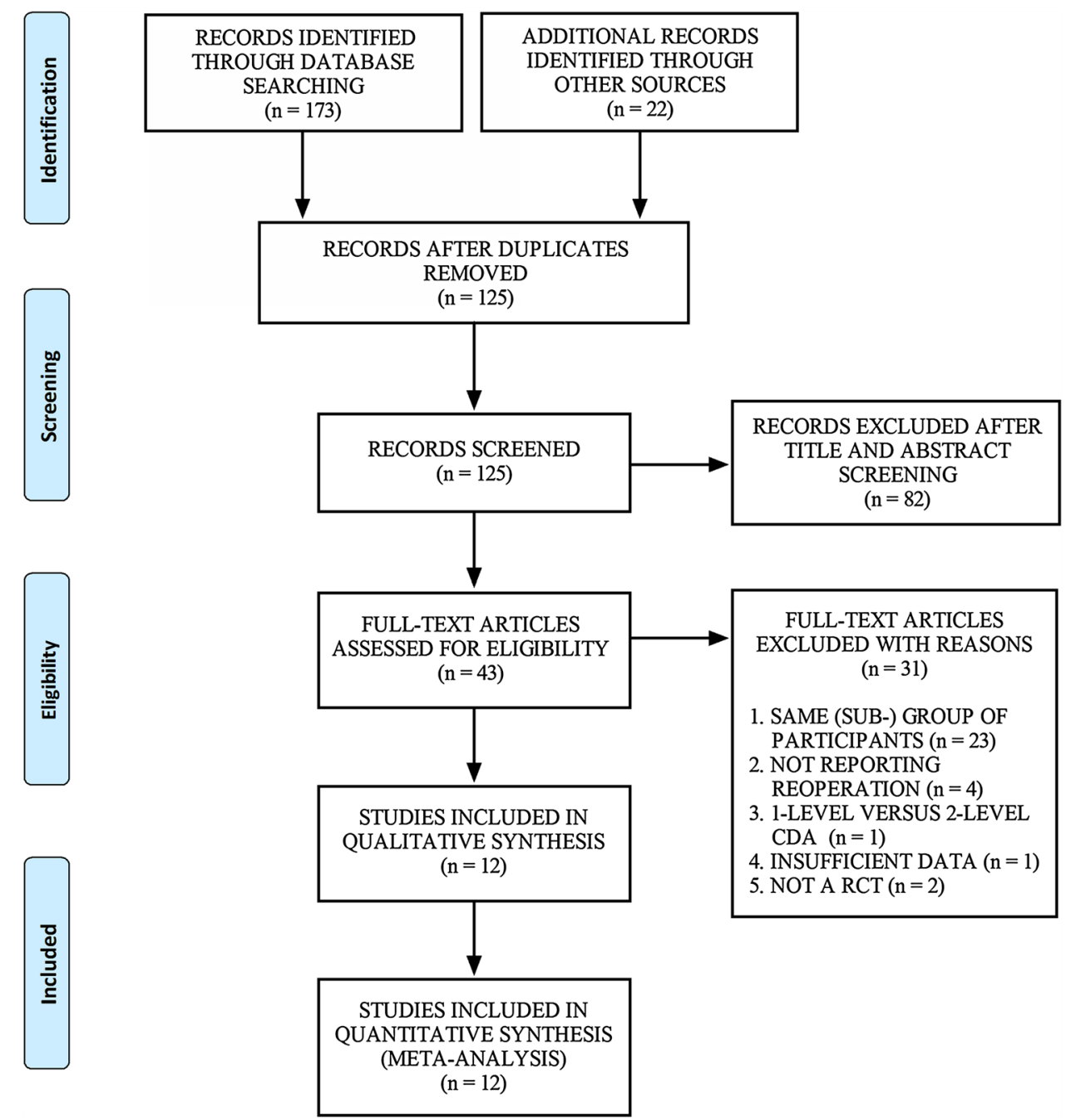

Fig. 1 The flow chart shows the process of publication selection. CDA = cervical disc arthroplasty; $\mathrm{RCT}=$ randomized controlled trial.

center trial [34], and nine of these studies were industrysponsored $[5,8,10,22,30,35,37,38,44]$.

\section{Risk of Bias Assessments}

Risk of bias was evaluated using the 12 criteria recommended in the 2009 updated Cochrane Back Review Group guidelines, which are based on Cochrane Handbook for Systematic Reviews of Interventions [16]. Random sequence generation, allocation concealment, blinding of patients, blinding of care providers, blinding of outcome assessment, dropout rate, intention-to-treat analysis, selective reporting, similar baseline, cointerventions, compliance, and identical timing outcome assessment were graded as low risk of bias, high risk of bias, or unclear risk of bias. Two reviewers (ZMZ and JSZ) independently applied these criteria to the selected studies.
Disagreements were resolved by consulting a third reviewer (JTC). A study was judged as having a low overall risk of bias when six or more of the 12 criteria were met and there were no serious methodologic flaws. In this metaanalysis, 12 included articles were considered to meet at least six of the 12 criteria, without serious flaws, and were rated as "low risk of bias" (Fig. 2).

Publication Bias

A funnel plot was constructed to assess the publication bias. The shape of the funnel plot was asymmetric, suggesting the existence of publication bias (Fig. 3); that is, the shape of the plot suggests that smaller negative or nodifference studies may have been performed but have not been published, and so were not identified and included in this meta-analysis. 


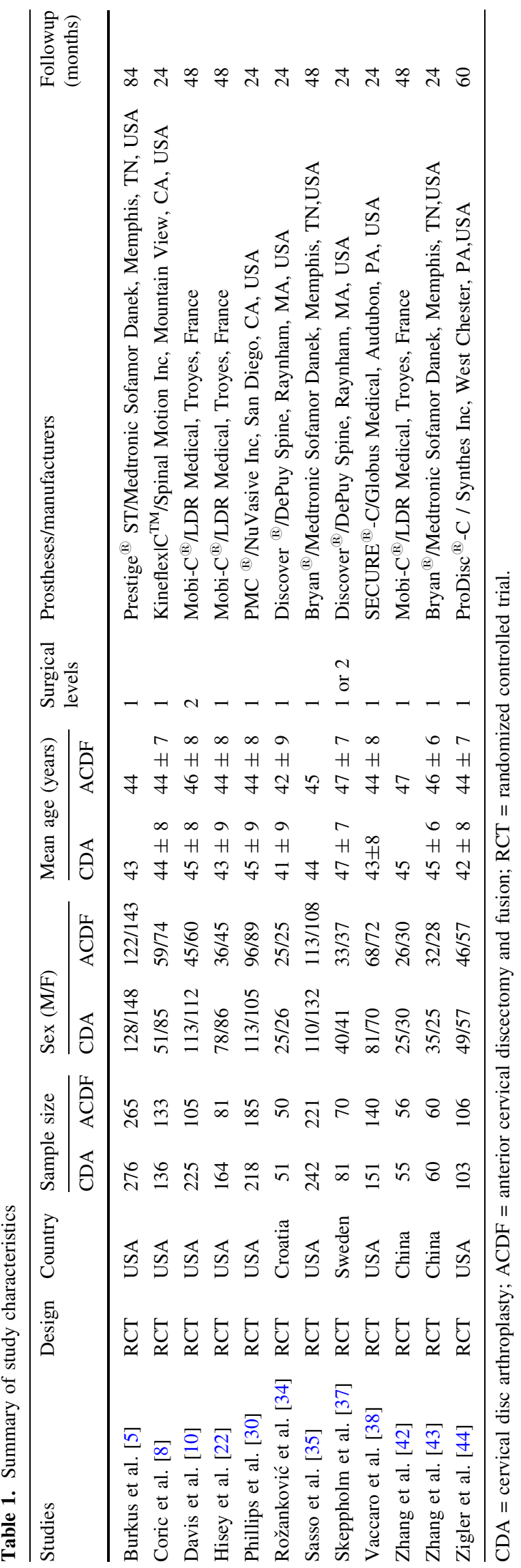

Data Analysis

When pooling the data from the included studies, the number of patients requiring secondary surgeries was combined rather than the number of levels or number of surgeries (Appendix 1. Supplemental material is available with the online version of $C O R R^{\circledR}$ ). When performing subgroup analyses based on secondary surgical level, some patients undergoing reoperations at the index and adjacent levels were counted simultaneously in the analyses of index-level and adjacent-level procedures. Patients undergoing external bone growth stimulator or nonadjacent-level procedures were not included in this meta-analysis.

The meta-analysis was performed using Review Manager (RevMan) software, Version 5.3 (Nordic Cochrane Centre, Copenhagen, Denmark). Only dichotomous outcomes were mentioned in our study. Risk ratio (RR) and the accompanying $95 \%$ CI were calculated for dichotomous variables, and a p value of 0.05 or less was considered statistically significant. Heterogeneity was evaluated using the chi-square test and the $\mathrm{I}^{2}$ statistic [20]. When the probability was less than 0.05 and $\mathrm{I}^{2}$ greater than $50 \%$, heterogeneity was considered significant across studies and the meta-analysis was performed in a randomeffects model. Otherwise, a fixed-effects model was used.

\section{Results}

Overall Frequency of Reoperation at Index and Adjacent Levels

Patients in the cervical disc arthroplasty group underwent fewer secondary surgical procedures than did patients in the anterior cervical discectomy and fusion group (RR, 0.54; 95\% CI, 0.36-0.80; p = 0.002) (Fig. 4). The overall frequency of reoperation at the index and adjacent levels was 6\% (108 of 1762) in the cervical disc arthroplasty group and $12 \%$ (171 of 1472) in the anterior cervical discectomy and fusion group, respectively. There was significant heterogeneity across studies $\left(\mathrm{p}=0.01 ; \mathrm{I}^{2}=\right.$ $55 \%$ ), and the random-effects model was used.

Frequency of Reoperation at the Index Level

Pooled analysis showed that patients treated with cervical disc arthroplasty were less likely to undergo reoperation at the index level compared with patients treated with anterior cervical discectomy and fusion (RR, 0.50; 95\% CI, 0.37$0.68 ; \mathrm{p}<0.001$ ) (Fig. 5). The frequency of reoperation at the index level was $4 \%$ (65 of 1647) in the cervical disc arthroplasty group and 8\% (104 of 1356) in the anterior 


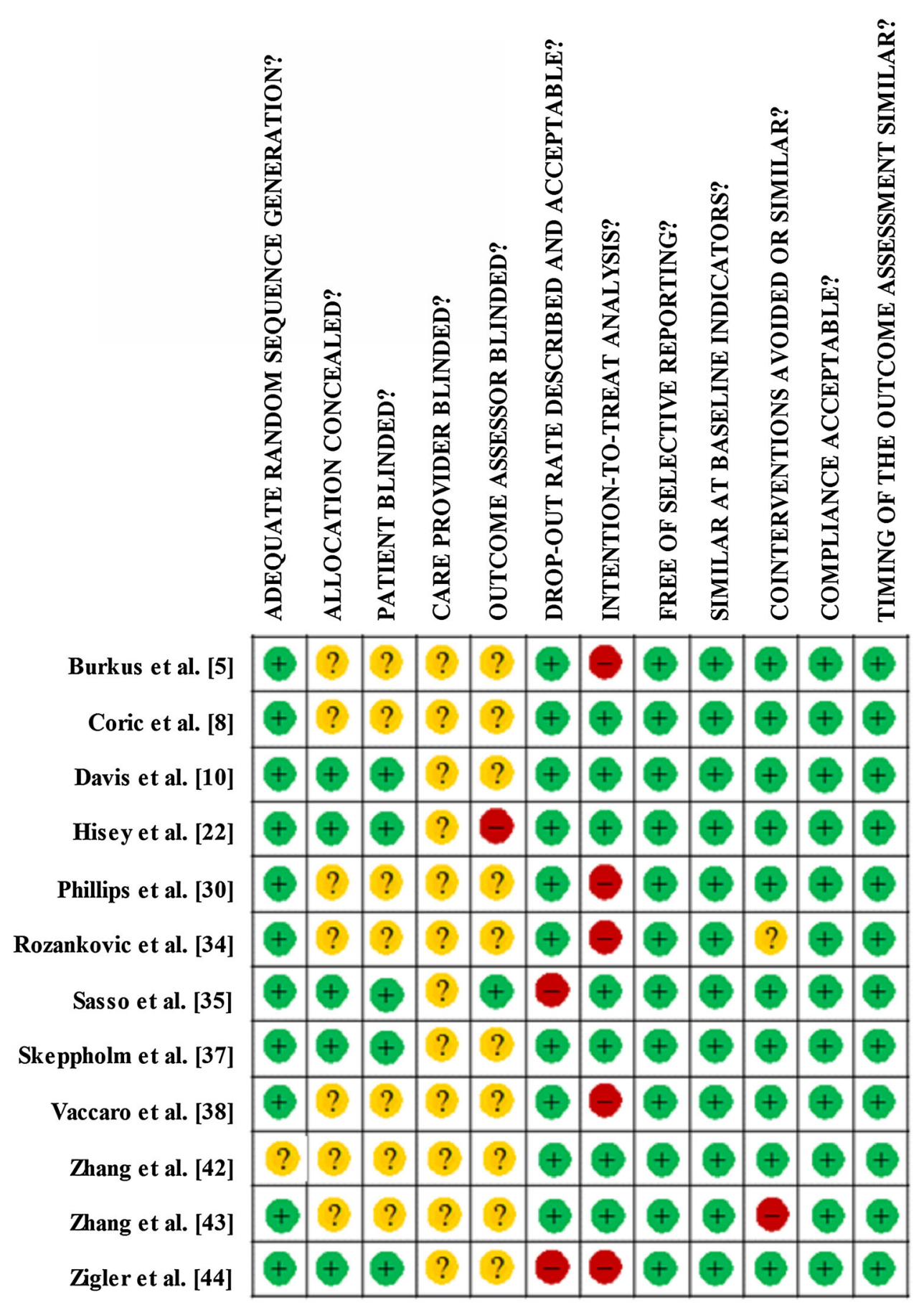

Fig. 2 Assessment of risk of bias for the included studies is shown. $+=$ low risk of bias; $-=$ high risk of bias; ? = unclear risk of bias.

cervical discectomy and fusion group, respectively. There was no significant heterogeneity across studies $(\mathrm{p}=0.08$; $\left.\mathrm{I}^{2}=42 \%\right)$, and a fixed-effects model was used.

Frequency of Reoperation at the Adjacent Level

Pooled analysis showed patients in the cervical disc arthroplasty were less likely to undergo reoperation at adjacent levels than were patients in the anterior cervical discectomy and fusion group (RR, 0.52; 95\% CI, $0.37-0.74 ; \mathrm{p}<0.001$ ) (Fig. 6). The frequency of reoperation at the adjacent level was 3\% (49 of 1711) in the cervical disc arthroplasty group and 8\% (81 of 1422) in the anterior cervical discectomy and fusion group, respectively. No heterogeneity was detected among studies $\left(\mathrm{p}=0.48 ; \mathrm{I}^{2}=0 \%\right)$, and a fixed-effects model was used. 


\section{Discussion}

The anterior cervical discectomy and fusion has been shown to be effective in patients with cervical radiculopathy or myelopathy [4, 17]. Despite the success of this procedure, cervical fusion has some important shortcomings, including loss of segmental motion and persistence or recurrence of symptoms resulting in reoperation at either the index or adjacent levels. Concerns regarding these issues led to the design and development of the cervical disc arthroplasty. Compared with anterior cervical discectomy and fusion, the cervical disc arthroplasty offers the theoretical biomechanical advantage of preservation of motion at the index level, which reduces stresses at the adjacent levels [12, 13]. The equivalency or superiority of the cervical disc arthroplasty as an alternative to anterior cervical discectomy

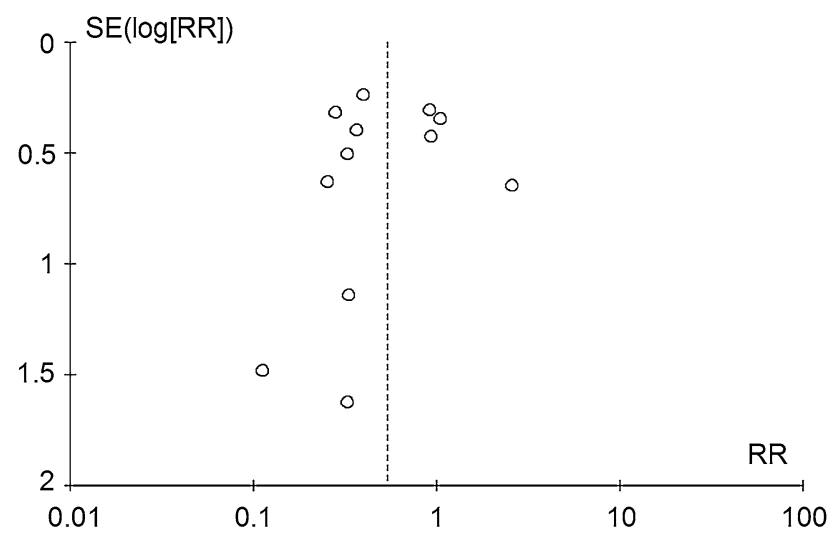

Fig. 3 A funnel plot of the included studies is asymmetric, indicating the presence of publication bias. $\mathrm{SE}=$ standard error; $\mathrm{RR}=$ risk ratio. and fusion has been seen in FDA Investigational Device Exemption and other studies [5, 7, 8, 10, 22, 30, 32, 34, 35, $37,38,42-44]$. However, there is controversy regarding whether the cervical disc arthroplasty results in a lower frequency of reoperation compared with the anterior cervical discectomy and fusion. We therefore performed a metaanalysis of randomized trials to compare the frequency of reoperation after these two procedures, at a minimum of 2 years of followup. We found that patients undergoing cervical disc arthroplasty had a substantially lower likelihood of undergoing reoperation between 2 and 7 years after surgery than did patients undergoing anterior cervical discectomy and fusion.

Our study has several limitations. First, our funnel plot (Fig. 3) suggested the presence of positive-outcome bias in the population of studies we identified. This means that it is likely that smaller studies have been performed but have not been published, and so were not available for our analysis. The effect of positive-outcome bias, if present, would be to inflate the apparent benefits of the cervical disc arthroplasty. Although we cannot prove this, we caution the reader that the effect sizes and apparent clinical benefits of cervical disc arthroplasty therefore might be overestimated in our meta-analysis. We encourage others to publish their work regardless whether the results are positive or negative to mitigate this issue. Second, nine of the 12 included studies were industry funded. This might limit the generalizability of our findings and introduce a potential bias in favor of cervical disc arthroplasty. Results in our meta-analysis therefore should be interpreted with some caution. Given the rapidly growing market of cervical disc prostheses, the potential bias could be nullified and controlled in more

Risk Ratio Risk Ratio

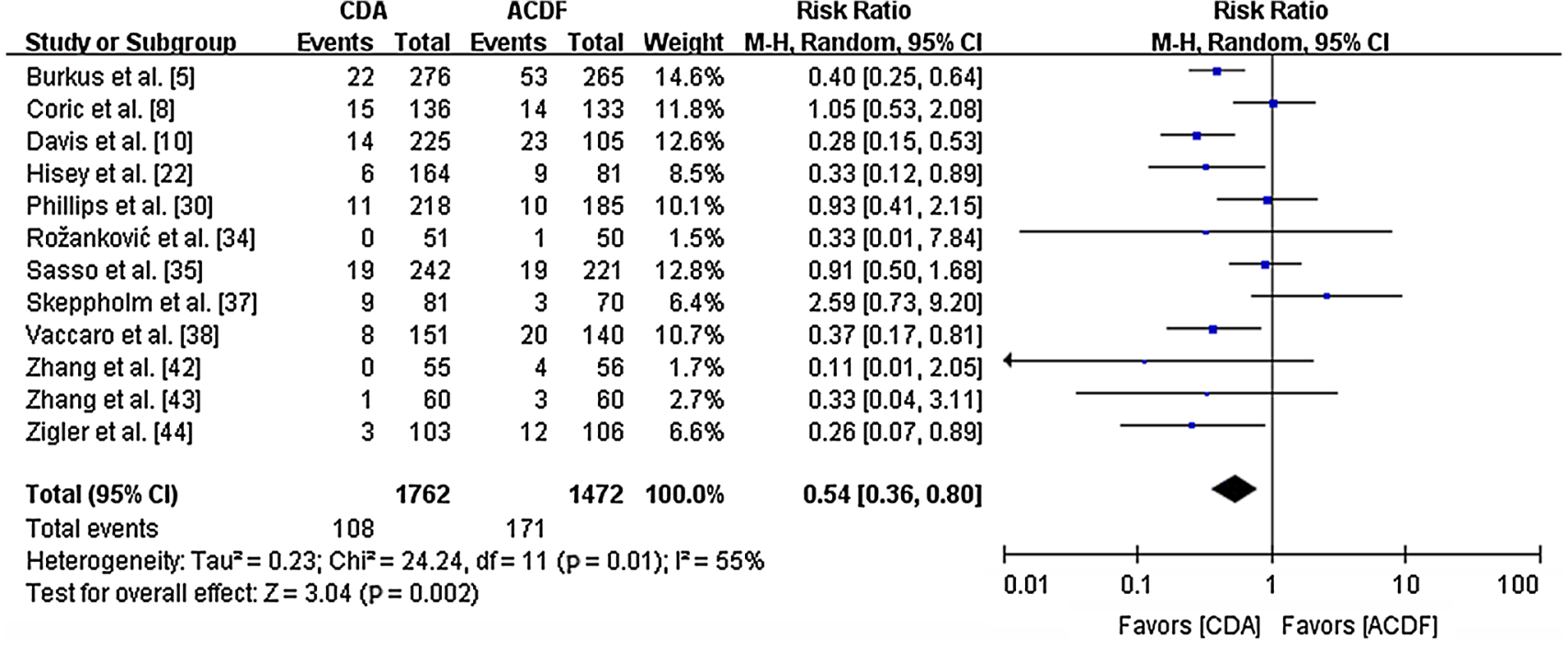

Fig. 4 The forest plot shows the overall frequency of reoperation at the index and adjacent levels after cervical disc arthroplasty versus anterior cervical discectomy and fusion. The size of the squares reflects the weight of the trial in pooled analysis. The horizontal bars represent the $95 \%$ CI. MH $=$ Mantel-Haenszel; df $=$ degrees of freedom; $\mathrm{CDA}=$ cervical disc arthroplasty; $\mathrm{ACDF}=$ anterior cervical discectomy and fusion. 


\begin{tabular}{|c|c|c|c|c|c|}
\hline Study or Subgroup & $\begin{array}{l}\text { CDA } \\
\text { Events } \\
\end{array}$ & Total & $\begin{array}{l}\text { ACDI } \\
\text { Events }\end{array}$ & F Total & Weight \\
\hline Burkus et al. [5] & 11 & 276 & 29 & 265 & $25.6 \%$ \\
\hline Coric et al. [8] & 6 & 136 & 7 & 133 & $6.1 \%$ \\
\hline Davis et al. [10] & 9 & 225 & 16 & 105 & $18.9 \%$ \\
\hline Hisey et al. [22] & 5 & 164 & 8 & 81 & $9.3 \%$ \\
\hline Phillips et al. [30] & 11 & 218 & 10 & 185 & $9.4 \%$ \\
\hline Rožanković et al. [34] & 0 & 51 & 1 & 50 & $1.3 \%$ \\
\hline Sasso et al. [35] & 9 & 242 & 10 & 221 & $9.1 \%$ \\
\hline Skeppholm et al. [37] & 3 & 81 & 1 & 30 & $0.9 \%$ \\
\hline Vaccaro et al. [38] & 4 & 151 & 14 & 140 & $12.6 \%$ \\
\hline Zigler et al. [44] & 3 & 103 & 8 & 106 & $6.8 \%$ \\
\hline Total $(95 \% \mathrm{Cl})$ & & 1647 & & 1356 & $100.0 \%$ \\
\hline Total events & 65 & & 104 & & \\
\hline
\end{tabular}

Fig. 5 The forest plot shows the frequency of reoperation at the index level after cervical disc arthroplasty versus anterior cervical discectomy and fusion. The size of the squares reflects the weight of the trial in pooled analysis. The horizontal bars represent the

\section{Risk Ratio Risk Ratio}

M-H, Fixed, $95 \% \mathrm{Cl}$

$0.36[0.19,0.71]$

$0.84[0.29,2.43]$

$0.26[0.12,0.57]$

$0.31[0.10,0.91]$

$0.93[0.41,2.15]$

$0.33[0.01,7.84]$

$0.82[0.34,1.99]$

$6.05[0.76,47.98]$

$0.26[0.09,0.79]$

$0.39[0.11,1.41]$

$0.50[0.37,0.68]$

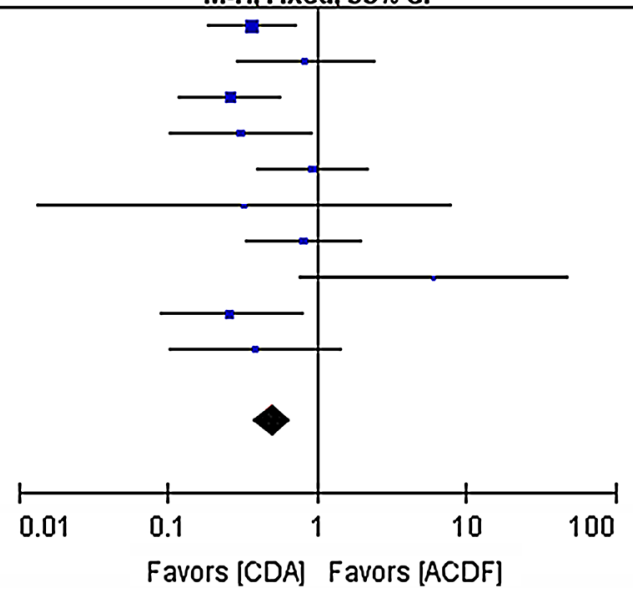

95\% CI. $\mathrm{MH}=$ Mantel-Haenszel; $\mathrm{df}=$ degrees of freedom; CDA = cervical disc arthroplasty; $\mathrm{ACDF}=$ anterior cervical discectomy and fusion.

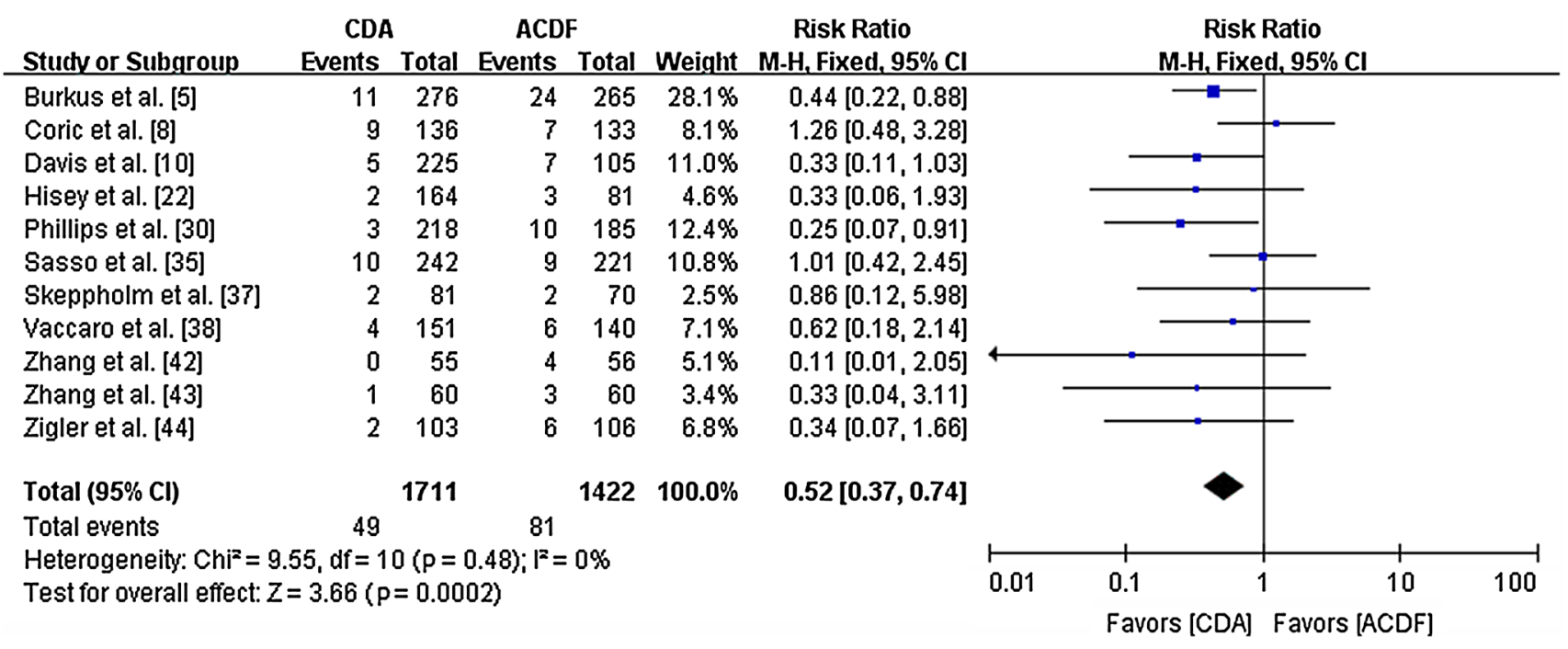

Fig. 6 The forest plot shows the frequency of reoperation at adjacent levels after cervical disc arthroplasty versus anterior cervical discectomy and fusion. The size of the squares reflects the weight of the trial

nonindustry-sponsored studies on this topic, which would help surgeons know the degree to which these findings will generalize in the practice community. Third, only one of 12 studies used an autograft; the other 11 used allografts. An autograft provides better conditions for bone fusion and a higher fusion rate compared with allograft $[15,36]$. The use of allografts could increase the risk of pseudarthrosis and the frequency of reoperation in the control group. This also could introduce a potential bias in favor of cervical disc arthroplasty. Therefore, we encourage investigators to use the gold standard autograft in future studies. Fourth, eight different types of prostheses were used in the included studies. Clinical heterogeneity might be caused by the

in pooled analysis. The horizontal bars represent the $95 \%$ CI. $\mathrm{MH}=$ Mantel-Haenszel; $\mathrm{df}=$ degrees of freedom; $\mathrm{CDA}=$ cervical disc arthroplasty; $\mathrm{ACDF}=$ anterior cervical discectomy and fusion.

properties of the different prostheses. However, it currently is not feasible to perform a subgroup analysis because of the paucity of studies for each type of prosthesis. Fifth, two studies did not provide sufficient data regarding revision, removal, supplemental fixation, and additional surgery [5, $38]$. We could do only the combined analysis for reoperation at the index level, but not a subgroup analysis for these procedures.

In this meta-analysis, we provided evidence of a higher frequency of reoperation at the index level in the anterior cervical discectomy and fusion group compared with the cervical disc arthroplasty group. Secondary surgical procedures at the index level in the patients undergoing anterior 
cervical discectomy and fusion were performed mainly for pseudarthrosis and a few for instrumentation failure, dislodgement, dysphagia, or cervical stenosis $[8,10,22,30,34$, 44]. One potential benefit of the cervical disc arthroplasty is elimination of the risk of pseudarthrosis, which theoretically is helpful in reducing the risk of reoperation at the index level. However, the cervical disc arthroplasty is associated with some challenges including migration, subsidence, heterotopic ossification, and wear debris $[3,26]$. In the current study, the cervical disc arthroplasty group yielded a relatively low frequency of reoperation at the index level (4\%). Most of these surgical procedures were for persistent or recurring neck pain without device failure, but some were device-related such as device malposition, migration, or subsidence $[8,10,22,30,37,44]$. Wear debris causing osteolysis is known as a late complication of the large joint arthroplasty [6, 18]. The cervical disc arthroplasty is designed for younger healthy patients with disc degeneration. The younger population would experience the greatest amount of prosthesis wear and tear owing to time and activity level [26]. Despite no cases of wear debris reported in the studies included in our meta-analysis, future studies with larger samples and longer-term followups are needed to examine this issue.

The principal disadvantage of the anterior cervical discectomy and fusion is that the loss of movement in the fusion segment places increased stresses on adjacent levels. It has been postulated that the biomechanical alterations after fusion accelerate degeneration of the adjacent segment and may result in symptomatic adjacent-segment degeneration $[14,21,24]$. The motivation behind the design and adoption of the cervical disc arthroplasty is to reduce or prevent adjacent-segment degeneration and thus to reduce the potential of symptomatic adjacent-segment degeneration requiring surgery. However, three published meta-analyses yielded inconsistent results regarding whether the cervical disc arthroplasty was associated with a reduced frequency of symptomatic adjacent-segment degeneration requiring surgery [25, 40, 41]. In our metaanalysis, a total of 11 included studies reported the adjacent-segment surgical cases. All adjacent-segment procedures were in response to symptomatic adjacent-segment degeneration. Our study had a larger sample size and included the latest RCTs compared with previous metaanalyses [25, 40, 41]. We found that the frequency of reoperation at the adjacent level was lower in the cervical disc arthroplasty group than in the anterior cervical discectomy and fusion group. Results of our meta-analysis suggest that the cervical disc arthroplasty is associated with fewer reoperations than the anterior cervical discectomy and fusion, indicating that the cervical disc arthroplasty is a safe and effective alternative to fusion for cervical radiculopathy and myelopathy. This information would be useful in educating patients and surgeons during the informed consent process. However, our results should be interpreted cautiously because of some limitations inherent to this meta-analysis. Additional prospective randomized studies with larger sample sizes and longer-term followups are necessary to update this meta-analysis to better evaluate the frequency of reoperation after cervical disc arthroplasty.

\section{References}

1. Anderson PA, Hashimoto R. Total disc replacement in the cervical spine: a systematic review evaluating long-term safety. Evid Based Spine Care J. 2012;3(suppl 1):9-18.

2. Beutler W, Myer J, Lindley JG Jr, Baker K. The role of cervical arthroplasty in reducing the incidence of secondary surgery. Spine J. 2012;12(suppl):S81-S82.

3. Blumenthal SL, Ohnmeiss DD, Guyer RD, Zigler JE. Reoperations in cervical total disc replacement compared with anterior cervical fusion: results compiled from multiple prospective food and drug administration investigational device exemption trials conducted at a single site. Spine (Phila Pa 1976). 2013;38:11771182.

4. Bohlman HH, Emery SE, Goodfellow DB, Jones PK. Robinson anterior cervical discectomy and arthrodesis for cervical radiculopathy: long-term follow-up of one hundred and twenty-two patients. J Bone Joint Surg Am. 1993;75:1298-1307.

5. Burkus JK, Traynelis VC, Haid RW Jr, Mummaneni PV. Clinical and radiographic analysis of an artificial cervical disc: 7-year follow-up from the Prestige prospective randomized controlled clinical trial: clinical article. J Neurosurg Spine. 2014;21:516528.

6. Callaghan JJ, Liu SS, Firestone DE, Yehyawi TM, Goetz DD, Sullivan J, Vittetoe DA, O'Rourke MR, Johnston RC. Total hip arthroplasty with cement and use of a collared matte-finish femoral component: nineteen to twenty-year follow-up. $J$ Bone Joint Surg Am. 2008;90:299-306.

7. Cheng L, Nie L, Li M, Huo Y, Pan X. Superiority of the Bryan (®) disc prosthesis for cervical myelopathy: a randomized study with 3-year followup. Clin Orthop Relat Res. 2011;469:3408-3414.

8. Coric D, Nunley PD, Guyer RD, Musante D, Carmody CN, Gordon CR, Lauryssen C, Ohnmeiss DD, Boltes MO. Prospective, randomized, multicenter study of cervical arthroplasty: 269 patients from the Kineflex|C artificial disc investigational device exemption study with a minimum 2-year follow-up: clinical article. J Neurosurg Spine. 2011;15:348-358.

9. Davis RJ, Hoffman GA, Bae HW, Hisey MS, Rashbaum RE, Nunley PD, Peterson DL, Stokes J. Cervical disc arthroplasty results in fewer secondary surgeries through 48 months compared to ACDF: results for a prospective randomized IDE study for two-level use. Spine J. 2013;13(suppl): S164-S165.

10. Davis RJ, Nunley PD, Kim KD, Hisey MS, Jackson RJ, Bae HW, Hoffman GA, Gaede SE, Danielson GR 3rd, Gordon C, Stone MB. Two-level total disc replacement with Mobi-C cervical artificial disc versus anterior discectomy and fusion: a prospective, randomized, controlled multicenter clinical trial with 4-year follow-up results. J Neurosurg Spine. 2015;22:15-25.

11. Delamarter RB, Zigler J. Five-year reoperation rates, cervical total disc replacement versus fusion, results of a prospective randomized clinical trial. Spine (Phila Pa 1976). 2013;38:711-717.

12. DiAngelo DJ, Roberston JT, Metcalf NH, McVay BJ, Davis RC. Biomechanical testing of an artificial cervical joint and an anterior cervical plate. J Spinal Disord Tech. 2003;16:314-323. 
13. Duggal N, Pickett GE, Mitsis DK, Keller JL. Early clinical and biomechanical results following cervical arthroplasty. Neurosurg Focus. 2004;17:E9.

14. Eck JC, Humphreys SC, Lim TH, Jeong ST, Kim JG, Hodges SD, An HS. Biomechanical study on the effect of cervical spine fusion on adjacent-level intradiscal pressure and segmental motion. Spine (Phila Pa 1976). 2002;27:2431-2434.

15. Epstein NE. Iliac crest autograft versus alternative constructs for anterior cervical spine surgery: pros, cons, and costs. Surg Neurol Int. 2012;3(suppl 3):S143-S156.

16. Furlan AD, Pennick V, Bombardier C, van Tulder M; Editorial Board, Cochrane Back Review Group. 2009 updated method guidelines for systematic reviews in the Cochrane Back Review Group. Spine (Phila Pa 1976). 2009;34:1929-1941.

17. Gore DR, Sepic SB. Anterior discectomy and fusion for painful cervical disc disease: a report of 50 patients with an average follow-up of 21 years. Spine (Phila Pa 1976). 1998;23:20472051.

18. Griffin WL, Fehring TK, Pomeroy DL, Gruen TA, Murphy JA. Sterilization and wear-related failure in first- and second-generation press-fit condylar total knee arthroplasty. Clin Orthop Relat Res. 2007;464:16-20.

19. Heller JG, Sasso RC, Papadopoulos SM, Anderson PA, Fessler RG, Hacker RJ, Coric D, Cauthen JC, Riew DK. Comparison of BRYAN cervical disc arthroplasty with anterior cervical decompression and fusion: clinical and radiographic results of a randomized, controlled, clinical trial. Spine (Phila Pa 1976). 2009;34:101-107.

20. Higgins JP, Thompson SG. Quantifying heterogeneity in a metaanalysis. Stat Med. 2002;21:1539-1558.

21. Hilibrand AS, Carlson GD, Palumbo MA, Jones PK, Bohlman HH. Radiculopathy and myelopathy at segments adjacent to the site of a previous anterior cervical arthrodesis. J Bone Joint Surg Am. 1999;81:519-528.

22. Hisey MS, Bae HW, Davis RJ, Gaede S, Hoffman G, Kim KD, Nunley PD, Peterson D, Rashbaum RF, Stokes J, Ohnmeiss DD. Prospective, randomized comparison of cervical total disk replacement versus anterior cervical fusion: results at 48 months follow-up. J Spinal Disord Tech. 2015;28:E237-E243.

23. Jawahar A, Cavanaugh DA, Kerr ER 3rd, Birdsong EM, Nunley PD. Total disc arthroplasty does not affect the incidence of adjacent segment degeneration in cervical spine: results of 93 patients in three prospective randomized clinical trials. Spine J. 2010;10:1043-1048.

24. Lee JC, Lee SH, Peters C, Riew KD. Adjacent segment pathology requiring reoperation after anterior cervical arthrodesis: the influence of smoking, sex, and number of operated levels. Spine (Phila Pa 1976). 2015;40:E571-E577.

25. Luo J, Gong M, Huang S, Yu T, Zou X. Incidence of adjacent segment degeneration in cervical disc arthroplasty versus anterior cervical decompression and fusion meta-analysis of prospective studies. Arch Orthop Trauma Surg. 2015;135:155-160.

26. Moatz B, Tortolani PJ. Cervical disc arthroplasty: pros and cons. Surg Neurol Int. 2012;3(suppl 3):S216-S224.

27. Moher D, Liberati A, Tetzlaff J, Altman DG; PRISMA Group. Preferred reporting items for systematic reviews and meta-analyses: the PRISMA statement. Int J Surg. 2010;8:336-341.

28. Nandyala SV, Marquez-Lara A, Fineberg SJ, Singh K. Comparison of revision surgeries for one- to two-level cervical TDR and ACDF from 2002 to 2011. Spine J. 2014;14:2841-2846.

29. Nunley PD, Jawahar A, Cavanaugh DA, Gordon CR, Kerr ER, Utter PA. Symptomatic adjacent segment disease after cervical total disc replacement: re-examining the clinical and radiological evidence with established criteria. Spine J. 2013;13:5-12.

30. Phillips FM, Lee JY, Geisler FH, Cappuccino A, Chaput CD, DeVine JG, Reah C, Gilder KM, Howell KM, McAfee PC. A prospective, randomized, controlled clinical investigation comparing PCM cervical disc arthroplasty with anterior cervical discectomy and fusion: 2-year results from the US FDA IDE clinical trial. Spine (Phila Pa 1976). 2013;38:E907-918.

31. Radcliff K, Zigler J, Zigler J. Costs of cervical disc replacement versus anterior cervical discectomy and fusion for treatment of single-level cervical disc disease: an analysis of the Blue Health Intelligence database for acute and long-term costs and complications. Spine (Phila Pa 1976). 2015;40:521-529.

32. Riina J, Patel A, Dietz JW, Hoskins JS, Trammell TR, Schwartz DD. Comparison of single-level cervical fusion and a metal-onmetal cervical disc replacement device. Am J Orthop (Belle Mead NJ). 2008;37:E71-77.

33. Robertson JT, Papadopoulos SM, Traynelis VC. Assessment of adjacent-segment disease in patients treated with cervical fusion or arthroplasty: a prospective 2-year study. J Neurosurg Spine. 2005;3:417-423.

34. Rozankovic M, Marasanov SM, Vukic M. Cervical disc replacement with Discover versus fusion in a single level cervical disc disease: a prospective single center randomized trial with a minimum two-year follow-up. J Spinal Disord Tech. 2014 Sep 8. [Epub ahead of print]

35. Sasso RC, Anderson PA, Riew KD, Heller JG. Results of cervical arthroplasty compared with anterior discectomy and fusion: fouryear clinical outcomes in a prospective, randomized controlled trial. J Bone Joint Surg Am. 2011;93:1684-1692.

36. Shriver MF, Lewis DJ, Kshettry VR, Rosenbaum BP, Benzel EC, Mroz TE. Pseudoarthrosis rates in anterior cervical discectomy and fusion: a meta-analysis. Spine J. 2015;15:2016-2027.

37. Skeppholm M, Lindgren L, Henriques T, Vavruch L, Lofgren H, Olerud C. The Discover artificial disc replacement versus fusion in cervical radiculopathy: a randomized controlled outcome trial with 2-year follow-up. Spine J. 2015;15:1284-1294.

38. Vaccaro A, Beutler W, Peppelman W, Marzluff JM, Highsmith J, Mugglin A, DeMuth G, Gudipally M, Baker KJ. Clinical outcomes with selectively constrained SECURE-C cervical disc arthroplasty: two-year results from a prospective, randomized, controlled, multicenter investigational device exemption study. Spine (Phila Pa 1976). 2013;38:2227-2239.

39. van Eck CF, Regan C, Donaldson WF, Kang JD, Lee JY. The revision rate and occurrence of adjacent segment disease after anterior cervical discectomy and fusion: a study of 672 consecutive patients. Spine (Phila Pa 1976). 2014;39:2143-2147.

40. Verma K, Gandhi SD, Maltenfort M, Albert TJ, Hilibrand AS, Vaccaro AR, Radcliff KE. Rate of adjacent segment disease in cervical disc arthroplasty versus single-level fusion: meta-analysis of prospective studies. Spine (Phila Pa 1976). 2013;38:2253-2257.

41. Yang B, Li H, Zhang T, He X, Xu S. The incidence of adjacent segment degeneration after cervical disc arthroplasty (CDA): a meta analysis of randomized controlled trials. PLoS One. 2012; 7:e35032.

42. Zhang HX, Shao YD, Chen Y, Hou Y, Cheng L, Si M, Nie L. A prospective, randomised, controlled multicentre study comparing cervical disc replacement with anterior cervical decompression and fusion. Int Orthop. 2014;38:2533-2541.

43. Zhang X, Zhang X, Chen C, Zhang Y, Wang Z, Wang B, Yan W, Li M, Yuan W, Wang Y. Randomized, controlled, multicenter, clinical trial comparing BRYAN cervical disc arthroplasty with anterior cervical decompression and fusion in China. Spine (Phila Pa 1976). 2012;37:433-438.

44. Zigler JE, Delamarter R, Murrey D, Spivak J, Janssen M. ProDisc-C and anterior cervical discectomy and fusion as surgical treatment for single-level cervical symptomatic degenerative disc disease: five-year results of a Food and Drug Administration study. Spine (Phila Pa 1976). 2013;38:203-209. 